\title{
THE MEASUREMENT OF POLICE OUTPUT: CONCEPTUAL ISSUES AND ALTERNATIVE APPROACHES
}

\author{
ROBERT C. LIND* AND JoHN P. LIPSKY***
}

Soaring crime rates and law enforcement costs have produced widespread disillusionment and disenchantment with our criminal justice system. Even those who operate its basic institutions, police officers, judges, and correctional officials, are frequent critics of its performance, although they often differ about what is wrong. The mood of the country with regard to crime and law enforcement "is one of frustration and bewilderment." 1 This discontent has resulted in the questioning of our basic law enforcement institutions and our basic concepts of justice. While the system as a whole has been subjected to critical re-examination, the evaluation of performance has focused on the police. What we have been asking ourselves and our public officials is, can we stem the rising tide of crime, and if so, what will it cost? The attempt to obtain answers has raised additional questions. With regard to the police, the three critical questions are: (I) what do the police produce, or should they produce, and how can it be measured, (2) are the police producing at minimum cost, and (3) how much police service do we want to buy?

As we shall demonstrate, the answers to these questions are a part of the overall answer to the same set of questions posed for the criminal justice system as a whole. A fundamental tenet of this paper is that the activities of the police cannot be measured and evaluated without reference to the totality of criminal justice institutions and to the social environment in which these activities take place. This paper discusses the conceptual and practical difficulties of defining and measuring police output.

The first section sketches the overall problem of criminal justice resource allocation as it relates to the measurement of police output. We argue that police services are not a final product, but rather an intermediate product in the overall production of justice or law enforcement. The effectiveness of the police with regard to overall law enforcement depends not only on their own operations but on the operations of the courts, the prosecutor's office, the correctional system, and the other participants in law enforcement. We then introduce the concept of the social cost of crime and demonstrate that the problem of defining justice can be circumvented-

- Director, Institute for Public Policy Analysis, Stanford University.

** Special Assisant to the Director, Institute for Public Policy Analysis, Stanford University.

The authors wish to acknowledge financial support for the research done for this paper from the National Institute of Law Enforcement and Criminal Justice, Department of Justice grant number NI-7I-086-G. Source reference, Omnibus Crime Control and Safe Streets Act of $x 968$.

${ }^{1}$ Prestdent's Commisston on Law Enforcement and thie administration of Justice, The ChatLENGE OF CRIME iN A Free SOCIETY I (I967). 
for the purpose of determining the output of the criminal justice system-by measuring the level of justice produced by reductions in this social cost. In addition, if we posit that the social cost of crime increases with the number of offenses, then we can justify using crime rates to measure the output of the criminal justice system. Put in these terms, law enforcement is the product of the criminal justice system. With this approach we can analyze the product concept and the determinants of the optimum level of law enforcement.

The second section discusses a number of properties that various measures of police output should satisfy. The properties are related to three basic functions for which output measures are used: (I) program planning and evaluation, (2) evaluation of operating units, and (3) contracts for the sale of police services. The emphasis, however, is on measurement for program planning and evaluation, and, while measures are required for evaluating police performance at all levels from the individual patrolman or his unit on up, primary emphasis will be given to measuring total police services. Both cost-benefit and cost-effectiveness analysis are discussed in some detail.

The third section surveys a number of approaches to the measurement of police output. The strengths and weaknesses of each approach are then discussed with regard to the criteria set forth for output measures. Reference is made to a number of basic papers on the measurement of police services. The final section addresses the problem of the measurement of police output by examining the fundamental ways in which police actions can affect the crime rate. If it can be established that certain capabilities account for most of the police impact, then a measure of these capabilities may be a good proxy for police output. A number of possible measures are explored, and the additional empirical analysis required to validate these measures is outlined.

\section{I}

\section{SCARCITY AND JUSTICE}

Justice, like the attainment of virtually all good things, requires the use of scarce resources and therefore is in conflict with the other things that compete for these limited resources. ${ }^{2}$ The operation of criminal justice institutions requires personnel, capital equipment, and land as do other productive activities; and the use of these resources for the production of justice means foregoing the production of other goods. Put in financial terms, these resources must be purchased; the amount

\footnotetext{
${ }^{2}$ In this paper the term justice is used to denote the output of the criminal justice system, whatever that may be. This paper does not presume to deal with broader questions regarding the use of the term justice. Rather than inquiring into the essence and nature of a just society, a question of infinite dificulty, this paper will accept the scope for the activities of the criminal justice system as defined by existing laws. Concededly, the existing set of laws define a certain aspect and concept of justice, which, it might reasonably be contended, is deficient. However, this is not directly relevant to the main inquiry of this paper. Subsequently, the output of the criminal justice system will be defined in terms of reducing the social cost of crime.
} 
spent in the pursuit of justice can only be increased by spending less for something else. To obtain increased spending for criminal justice, funds must be diverted from other government programs or taxes must be raised, in which case private expenditure must be curtailed. Therefore, in considering the entire question of justice one must constantly weigh whether the incremental gains to society are worth their incremental costs. This leads to the realization that justice must be considered like all other goods that compete for our limited resources; scarcity requires us to strike compromises between the amounts of food, shelter, education, other goods and services, and justice which we ideally might desire. Consequently, justice becomes a matter of degree rather than an absolute commodity.

For these reasons an operational system for criminal justice cannot be evaluated in categorical terms of ethics or jurisprudence alone. To do so would eliminate from consideration the constraints placed on society by the limits of technology and resource availability and the fundamental choices which these limitations require. This point of view does not necessarily conflict with that of jurisprudence or ethics, but rather superimposes on them a framework for considering the choices and tradeoffs inherent in a world of technical limitations and scarce resources.

\section{A. Allocation of Resources Within the Justice Producing System}

Resource allocation for criminal justice can be analyzed in terms of three separate but mutually interdependent decisions: $(x)$ the decision regarding how much of society's resources are to be devoted to the production of justice, that is, the total budget to be allocated to the collectivity of institutions and agencies producing justice, (2) the decision as to what portion of the total expenditure will go to each of these production units, and (3) the decisions within each production unit concerning the allocation of funds among specific production tasks.

The first decision involves contrasting the incremental increases in justice against the incremental social costs of obtaining these increases. These social costs, measured in dollars, represent foregone opportunities to produce other goods and services. To arrive at the optimal expenditure on justice, the total spent should be increased as long as each incremental increase in justice is valued more highly than the incremental cost of obtaining it. The optimum is reached at the point at which the value of the last increment just equals its cost and where the cost of further increments exceeds their value. How much a community should spend on justice depends on how justice is valued with respect to other goods and services, the cost of justice relative to these goods and services, and the total wealth of the community. In general, the wealthier a community is, the more it will choose to spend on every government program. However, scarcity of resources implies that no community is rich enough to push expenditure on all or even any one commodity to a point where no one could benefit from the allocation of more resources to this commodity.

The determination of the amount which should be spent for justice will depend 
to some degree on how the total expenditure is to be allocated among the various production units and how it is to be allocated among various tasks within production units. Very different effects on the overall production of justice will be produced by a decision as to whether to dispense given funds to the correctional system or to the courts or to the police. Similarly, the amount of justice that can be obtained by any additional expenditure will depend on how these funds are used within the agencies to which they are allocated. Suppose that resources were allocated to the police and that they were earmarked for increasing the effectiveness of the police in solving crimes. This increased capability might result in an increase in the number of arrests which, in turn, would increase the number of cases which are brought before the court. The overall effect on justice of increased police effectiveness will depend in part on the effectiveness of the courts and correctional institutions as well. If as a result of delays in the court system it were impossible to prosecute the additional persons arrested, then the effect might be negligible. Thus, the contribution to justice by any one agency is critically dependent on the operation of other agencies within the system.

The essential point is that the level of justice produced-however justice may be defined-results from the collective action of those agencies and individuals who participate in the criminal justice system, and it is in this sense and for this reason that the criminal justice agencies must be considered as a system. This should not be construed to suggest that the agencies are organized to operate in a systematic and integrated way or that they perceive a need to pursue common objectives. In practice, quite the contrary appears to be true. To quote the Task Force on Law Enforcement of the Violence Commission, "Each participant sees the commission of crime, and the procedures of justice, from a different perspective. His daily experience and his set of values as to what effectiveness requires and what fairness requires are, therefore, likely to be different. As a result, the mission and priorities of a system of criminal justice will, in all likelihood, be defined differently by a policeman, a trial judge, a prosecutor, a defense attorney, a correctional administrator, an appellate tribunal, a slum dweller, and a resident of the suburbs."3 The police are part of this system, and the effect of their operation on the overall provision of justice depends not only on their own actions but on the manner in which the rest of the system is operated.

The police are essentially in the position of a firm that produces an intermediate product that will be used as an input to the production of a final product called justice. That is, they produce services that are not desired as such, but only because they contribute to a final objective or output. For example, individuals do not derive utility directly from the existence of crime-related police activities; rather,

\footnotetext{
'Task Force of Law and Law Enforcement, Law and Order Reconstdered: Report to The National Commission on The Cruses and Prevention of Viotence 267 (J. Campbell, J. Sahid \& D. Stang eds. 1969 ).
} 
they demand these services as a part of the total activity of crime control. In the absence of crime, most of us would happily dispense with these police functions.

Looking at the police in this way gives us an insight into the problems of measuring police output. First, economic theory tells us that the value of an intermediate product must be measured in terms of its contribution to the final product. Ideally we would like to measure the contribution of police activity in terms of its contribution to justice. For example, in considering an increase in police patrols, we would like to be able to measure its impact on justice. This, however, requires a measure of justice which again confronts us with the problem of defining justice. The difficulty is that individuals with different backgrounds and philosophical positions will subscribe to different objectives and concepts of justice, and no one definition will command universal acceptance.

\section{B. The Social Cost of Crime}

The way economists have circumvented this definitional dilemma is to take our system of laws as given and to posit that the commission of crime involves the imposition of a cost on society. ${ }^{4}$ Furthermore, it is assumed that the social cost of crime is an increasing function of the number of offenses. This cost can be measured in monetary units and represents the amount that society would be willing to pay to eliminate crime. One conceptual experiment that could be performed to evaluate the social costs of crime would be to confront each individual with the possibility of trading income for reduced crime. The cost of a given number of offenses to an individual would be computed on the basis of the maximum amount that he would be willing to pay to reduce offenses from that level to zero. The social cost of crime would then be computed as the sum of these individual costs. This particular procedure will be explored in some detail when we discuss benefit-cost analysis with regard to police activity.

There are several advantages to this approach. First, it is completely general in that we can abstract the specific effects of crime that result in social costs which will be highly individual and non-uniform in nature. Thus, the framework is sufficiently broad to cover different concepts of justice and different definitions of crime. For example, crimes involving the mutual consent of those directly affected as well as crimes where there is a victim can be considered to result in social costs. The second advantage is that the output of the criminal justice system can be defined in terms of the reduction in the cost of crime, and, thus, the ambiguity inherent in comparing the reduction of different types of crimes can be eliminated.

\section{r. Inherent Costs}

While the output of the criminal justice system is the reduction of crime as measured by social cost, this does not imply that the optimum policy is to produce

\footnotetext{
'Different individuals, in general, will evaluate the cost of different crimes differently. For some individuals certain crimes may have a negative cost or represent a net gain.
} 
the maximum output, that is, to reduce crime to the lowest feasible level. Rather, we must consider the costs of the criminal justice system and weigh these against the benefits of reducing the social cost of crime. The costs of the criminal justice system include not only the direct resource costs of operating our criminal justice agencies-salaries for agency personnel and the cost of equipment-but also resource costs borne by private individuals. For example, the individual who is brought to trial must bear the cost of his defense, witnesses and juries contribute their time, and there are large private expenditures on crime protection. There are additional costs which are inherent in any system of law enforcement. Activities of law enforcement inevitably require some restriction of freedom, such as the imposition of occasional curfews or the closing of areas to allow police to operate more effectively. These restrictions generate costs. In addition, because of imperfect information, law enforcement agencies make mistakes, and these mistakes create costs for individual citizens. The police at times arrest innocent persons and the acts of proper investigation and interrogation may impose substantial costs on tnose who are involved. Similarly, courts sometimes convict and sentence innocent people. There is no way to completely eliminate this problem in a world of uncertainty. In statistical terms, the problem is one of a trade-off between two types of errors, errors occurring when the guilty are not convicted and errors occurring when the innocent are convicted. Under conditions of uncertainty, an increase in the probability of apprehending and convicting the guilty generally results in a simultaneous increase in the probability of apprehending and convicting the innocent. ${ }^{5}$ Finally, there are costs that arise when the authority vested in these agencies is abused. The existence of strong police powers which can be used to reduce crime opens the possibility of increased social cost from their abuse. Therefore, in computing the social costs of operating the criminal justice system, one must take into account not only the resource costs of these criminal justice agencies, but the resource costs that are incurred by private individuals and the implicit costs imposed by the operation of the system itself.

The objective of society in operating the criminal justice system should then be to minimize the combined social cost of crime and the social cost of the criminal justice system. This is the approach that has been adopted by economists who have recently addressed the question of resource allocation and law enforcement. ${ }^{6}$

\footnotetext{
"This point is explored in Harris, On the Economics of Law and Order, 78 J. Por. Econ. I65 (1970). The view that the criminal justice system is in some sense attempting to optimally trade off between the simultaneous minimization of the two types of errors corresponds to the dichotomous models of the system as presented in H. PACKER, The Limats of THE Crimrnar Sanction (I969). Packer constructs a Criminal Control Model which is concerned with convicting as many guilty parties as possible even at the expense of convicting innocent ones, and a Due Process Model which seeks to defend the rights of the defendant even at the expense of acquitting guilty parties.

'The basic work in a modern welfare economics analysis of crime is that of Gary Becker, Crime and Punishment: An Economic Approach, 76 J. Pot. EcoN. I69 (I968). Becker seeks to elaborate a social loss function, which defines the social cost of crimes. This function has four arguments, namely $\mathrm{L}=\mathrm{L}(\mathrm{D}, \mathrm{C}, \mathrm{b} f, \mathrm{O})$
} 


\section{Use of Statistics: The Crime Rate}

From a practical point of view, the critical problems inherent in analyzing the criminal justice system involve specifying the cost of crime and identifying and measuring the implicit or intangible costs that are associated with law enforcement itself. There is no generally accepted procedure for computing the social cost of crime and as a result the search for a measure of the system's output has focused on the use of the crime rate. By positing that the social cost of crime is an increasing function of the number of offenses and that the output of the criminal justice system is measured by the reduction in this cost, one can justify the statement that law enforcement is the output of the criminal justice system. Similarly, by comparing the costs of enforcement with the reduction in the cost of crime from improved enforcement, one can define the optimum level of enforcement.

The successful use of crime statistics to represent the social cost of crime in lieu of any satisfactory method for actually ascertaining these costs will depend in part upon our ability to weight crime data according to the seriousness of each crime. With such weighting, the data can be incorporated into a single index; without it the allocation of police resources would be distorted because an unweighted statistical measure would indicate that the deterrence of a relatively minor crime such as a $\$ 50$ larceny is equivalent to the deterrence of an armed robbery. To ciate, little effort has been made to systematically determine society's ranking of the seriousness of specific crimes. ${ }^{7}$ One must also keep in mind that crime rates are conditioned by both the existing laws and the population to which these laws apply. If either the laws or the population are varied, a change in the crime rate will result. In order to use crime statistics to evaluate the system's performance, a corrective factor must be included for differences in the basic population and the basic operative laws.

The relevant statistics for the purpose of evaluating crime rates are not the number of crimes reported to the police but are, instead, the actual number of crimes which occur. As has been well documented in the literature, the relationship be-

where: $D=$ the net "damage" stemming directly from criminal events, is an increasing function of the level of criminal activity.

$\mathrm{C}=$ the net cost function stemming from the cost of apprehension and conviction of criminals, also an increasing function of the level of criminal activity and of the probability, $p$, that any given criminal event will result in an arrest and conviction.

$\mathrm{bf}=$ the social cost of punishment, which is a function of the nature of punishment, $\mathrm{f}$, proscribed for each offense.

$O=$ the supply of criminal events, a function of $p$ and $f$ as well as of other considerations.

The policy variables accessible to the criminal justice system are $p$, the probability of arrest and conviction, and $f$, the punishment. The goal is to vary $p$ and $f$ so as to minimize $L$, the social cost (loss) from criminal events. An article by George Stigler, The Optimum Enforcement of Laws, 78 J. PoL. Ecos. 526 (1970) builds on Becker's analysis and concludes that "the goal of enforcement. . . is to achieve that degree of compliance with the rules of prescribed (or proscribed) behavior that the society believes it can afford" which implies that the marginal social return on enforcement be set equal to the marginal social cost.

${ }^{7}$ For examples of some attempts to derive a weighting system for crime statistics, see T. SELLN \& M. Wolfgang, The Measurement of Delinguency (I964) and President's Commission on Law Enforcement and the Administration of Justice, Crame and Its Inipact-AN Assessment (ig67). 
tween actual occurrences and reported occurrences may vary depending on a number of factors, such as the characteristics of the population base, police reporting practices, and so on. ${ }^{8}$ Thus, under carefully specified conditions, the performance of the police may be measured using indices based on crime rates; when so controlled, this measure satisfactorily reflects the contribution of the police to the output of criminal justice in the sense that a decrease in such a crime index will correspond to a decrease in the social cost of crime.

Even assuming that accurate statistics on the occurrence of criminal events were obtainable, significant difficulties in measuring police performance would remain due to the variations in the underlying characteristics of the population and the differential effects resulting from the activities of the rest of the criminal justice system. What is needed is a measure of police performance that relates to crime rates but which is independent of factors that the police cannot affect. This type of gauge would be useful not only in examining the impact of a change in police activity on crime, but would also help us to evaluate the level of effectiveness which is independently achieved by the police.

II

\section{Police Outrut Measures}

\section{A. Uses and Characteristics of Measures}

The major uses of police output measures are: (I) in management evaluation of operating units, (2) in contracts for police services, and (3) in program planning and evaluation. The required properties of a useful police output measure differ depending on the use for which the measure is needed. The social cost of crime and the number of crimes committed are not suited to serve as measures for all purposes.

\section{r. Assessing Operating Units}

The first use involves measuring the performance of operating units in order to evaluate whether they maintain acceptable performance standards. Most attempts by police departments to develop output measures have been for this purpose. For example, the number of arrests made by a traffic officer may be used to rate his productivity. The basic difference between the evaluation of operating units and the evaluation of programs to which these units contribute is that in the former the primary interest is in assessing how well a specific task is being performed while in the latter it is in judging the extent to which the performance of this task contributes to the production of justice.

Although the emphasis of this paper is not on the evaluation of individual

\footnotetext{
${ }^{8}$ See Wheeler, Criminal Statistics: A Reformulation of the Problem, 58 J. Cam. L.C.\&A.S. 3I7 (1967); Prestdent's Comangsion on Law Enforcenent and the Administration of Justice, Crime AND ITS IMIPACT-AN Assessment Ch. 2 (Ig67).
} 
functional units within the police, it is instructive to consider several properties that an output measure must have to serve this purpose. There must be an accepted rule for computing output, and the data necessary for this computation must be available. These two attributes are prerequisites if a measure is to be of practical use. Note that neither the social cost of crime nor a weighted crime index satisfy these conditions unless an accepted procedure for estimating the cost of crime or for weighting different crimes can be specified. These tasks are closely related since ideally crimes should be weighted in proportion to their social cost.

The third requirement for evaluating operating performance is that the effect on the measure of output of an operating unit can be isolated from the effects of other factors. As will become apparent, this condition is essential for contracting as well as for planning and evaluation. This problem, however, is most acute in evaluating small operating units within the police. As previously mentioned, one of the difficulties with using changes in crime rates to measure changes in police performance is that one may not be able to separate changes caused by the police from changes caused by other factors. This difficulty would be of absurd proportions if, for example, an attempt were made to measure the output of a single patrolman in terms of the crime rate. This example of the individual patrolman illustrates a fourth requirement. The output measure selected must be sufficiently sensitive to register the effect of the activity being considered. The problem of sensitivity is related to the problem of segregating the effects, or output, of a given activity from other factors, but it is primarily a question of isolating the effects of the activity from random fluctuations in the measure of output. This requires that the effect of the activity in question be large relative to such random variations.

It is thus posited that to be of practical use for evaluating operating performance, an output measure must have the four properties identified above. These attributes are also essential to contracting and to program planning and evaluation. There are many functional units within the police for which various output measures have been proposed. However, a complete discussion of these lies beyond the scope of this paper. The foregoing discussion has been included for completeness and because many of the measures that one encounters when dealing with the police are for evaluating internal performance. It is important that one consider these measures in terms of the function they serve.

\section{Contracting for Police Service}

The second use of output measures which we shall examine is in contracting for police service. In Los Angeles County, for example, communities within the County contract with the County for the provision of police services. Through area-wide consolidation of such activities as police training, laboratories, and record keeping, local communities are contracting for these inputs to the production of police services. While contracting for police services is not widespread at present, there is 
evidence that as communities seek new ways to obtain the cost savings and improved services associated with scale economies in production and at the same time retain control over the level and type of service they receive, contracting arrangements will increase. Contracting offers many of the advantages of consolidation without the loss of local control.

Clearly, to be used as a basis for contracting, a measure of what is to be provided must be defined by an unambiguous rule for computing what in fact is provided and the requisite data must be available for making such computations. In addition, the measure must be independent of other factors which may be beyond the control of either party to the contract. For example, if the County of Los Angeles were to contract with a local community for police services and payment were based on the rate of reported crime, then an increase in reporting or an increase in crime resulting from a change in the composition of the communityalthough totally unrelated to police activity-could lead to a decrease in measured police services and therefore a smaller payment. If, in fact, we could correct for all other factors, police service might be contracted on the basis of such a performance measure. Because other factors cannot be fully accounted for, in practice contracting has been based on the quantity of inputs such as the number of man-hours or vehicle-hours, and so on. Consequently, such contracts have more closely resembled employment contracts than sales contracts.

The basic problem in this situation is that the supplier wants to relate the measured product to the cost of producing it. However, if uncertainty regarding the relationship between the cost of production and the value of what is produced is too great, he may agree only to supply certain inputs for a given price; such an arrangement is essentially an employment contract. On the other hand, the buyer would prefer to relate what he pays to what he is getting in terms of his basic goals, that is-in the jargon of utility theory-in terms of the arguments in his utility function. Thus, a buyer of police services would like to have a contract written in terms of the crime rate; this would be like a sales contract where payment is based on the delivery of a desired product meeting given specifications. He may, however, accept the uncertain output associated with merely buying inputs to the final product if the reduction in the cost of obtaining a given, expected output is sufficiently great. An employment contract shifts uncertainty regarding the final output from the seller to the buyer. In theory one could eliminate this uncertainty by writing a contract specifying all possible contingencies; however, in practice, including these specifications may be impossible or simply too costly to make this a feasible alternative. ${ }^{10}$

\section{Program Planning and Evaluation}

Consider now the use of output measures in program planning and evaluation

${ }^{8}$ See Simon, A Formal Theory of the Employment Relationship, rg Economernics 293 (I951).

${ }^{10}$ Id. 
aimed at obtaining optimal resource allocation. Planning is the activity of identifying an'd relating alternative means to desired ends, and evaluation is the activity of determining which of the alternatives best achieves these ends. Therefore, it is basic to planning and evaluation than an objective exist. For this objective to be an operational one, it must be stated with sufficient precision to permit a determination of whether or not a specific program will contribute to the achievement of the objective. Unless goals can be stated in operational terms, it is not possible to relate means to ends with any confidence. For example, suppose that a stated objective of the police were to produce a secure community. Because there could be many possible interpretations of the meaning of "secure community," each having different implications for police operations, this statement does not meet the requirements of planning. If, however, we were to interpret the level of security to be the per capita incidence of crime, then the planner could develop programs directed to reducing crime.

The same problem arises in evaluation. Suppose that a planner is considering a new police program for increasing community security and that if this program is not adopted, the existing program will remain in effect. Our initial position is therefore the existing level and type of police activity which have produced the existing level of security. Evaluation requires that we determine whether by adopting the new program the level of security will increase, decrease, or remain the same. To accomplish this we must define security in such a way that given any two situations, we can unequivocally determine whether the level of security in the first is greater than, equal to, or less than the amount of security in the second. Thus, we need an operational decision rule, specified in advance, for determining what to observe and how to rank any two situations on the basis of what is observed. In technical terms, we must be able to define an ordinal ranking of all possible situations with regard to community security. This, in itself, is a first step toward quantification, because if we can establish a rule for deciding between the level of objective achievement in any two situations, then one can assign numbers to various levels of achievement, with higher numbers being assigned to higher levels of achievement. By so doing one quantifies objective achievement on a scale where only the ordinal properties of the scale are significant, that is, the only important property is whether one number is greater than another. How much greater or how many times as great is of no significance on such a scale. If a program produces an increase in the achievement of the objective, then the output of the program is this increase and can be measured in the same terms as the objective. Note that if we define security in terms of the per capita incidence of crime, this provides the desired ordinal ranking of all possible situations.

At this point a word of caution is in order. While it is true that planning and evaluation require that the objective be stated so that given two situations it can be determined whether one is better than another with respect to the achievement of 
that objective, this is not the only condition that a statement of purpose must meet. To be of practical use it must command widespread acceptance. We might redefine the objective of community security in terms of per capita incidence of crime only to find that a decrease in the incidence of crime was accompanied by a general feeling that the community was less secure. In this case, while the objective of security was stated in operational terms, the operational statement would not accurately reflect social judgement.

\section{B. The Cost of Producing Justice}

While it is important to be able to rank alternative situations with regard to an objective, in many cases we wish to compare levels of achievement or output with the costs of obtaining them. This is necessary in cost-benefit analysis, costeffectiveness analysis, and the evaluation of scale economies for determining the scale of production that minimizes unit costs. In some of these cases additional requirements must be imposed on the measure of police output.

\section{r. Cost-Benefit Analysis}

In cost-benefit analysis, the level of objective achievement is converted to a dollar value by estimating the values that would be obtained if one carried out the previously described procedure of allowing individuals to trade increments of achievement for income. The benefits to any single individual would be measured by his maximum willingness to pay for a reduction in crime, and total social benefits would be the sum of individual benefits. Stated in monetary units, benefits could then be compared with costs. The cost-benefit criterion directs that if the benefits of a program exceed its costs, the program should be undertaken. If there are two mutually exclusive alternatives, both of whose benefits exceed their costs, then the program which maximizes net benefit should be chosen. ${ }^{11}$

Returning to the example of measuring community security in terms of the per capita incidence of crime, the measurement of benefits would require a procedure for computing the total amount that individuals in the community would willingly pay for each reduction in the incidence of crime. Because police services or security are not generally marketed, there is no evidence from direct transactions on which to base an estimate of benefits. As in the case of most publicly produced goods, one can only infer from other types of evidence the value that people attach to reducing the incidence of crime.

Measuring the benefits from a reduction in crime is essentially equivalent to measuring the social cost of crime. It is an area of investigation that has recently attracted the attention of economists. At present, this type of analysis contains a number of unresolved methodological issues as well as data problems. Among the most important of these decisions regarding methodology is whether one should include

\footnotetext{
${ }^{11}$ For an explanation of the issues involved in benefit-cost analysis, see LIND, Benefit-Cost Analysis: a Criterion for Social Investment, in Water Resources Managenent and Pub. Polict (Ig68).
} 
benefits and costs to all individuals or whether benefits and costs to individuals committing illegal acts should be excluded. ${ }^{12}$ For example, should the exchange of goods that takes place through theft be considered a cost of crime or a transfer of goods with an offsetting benefit to the criminal who obtains the stolen goods? Most economists would agree that there is some loss from theft because stolen goods are worth less simply as a result of being "hot" items which cannot be distributed through legal channels. However, whether the total value of goods stolen' should be counted as a social cost is an issue which has not been resolved. The answer makes a significant difference in evaluating certain crime control programs.

In general, the threat of crime imposes on an individual a random variable representing possible losses just as does the threat of an earthquake, typhoon, disease, or any other phenomenon that may harm that individual. To the extent that the individual can and does fully insure against such occurrences, the maximum premium he pays reflects the costs from the threat of crime. Yet, one cannot fully insure against many crimes either because the necessary insurance is not available or because one cannot restore life or health impaired by crime. Therefore, many of the costs of the threat of crime remain uninsured. As a result, individuals may change their patterns of life and invest in private means of protection against crime. They may change residences, stay home at night, and invest in locks and other security measures to reduce the risk of being a victim. All of these represent costs that the individual incurs. Many of these costs can be observed and used in constructing a lower bound on the total social cost of crime.

A conceptual problem exists for so-called "crimes without victims" in which the only people directly affected by the criminal act have freely consented to it. Individuals not directly affected by such crimes feel they have a stake in such behavior or laws against the acts would not exist. However, it is not clear how one would assess the price individuals in society would be willing to pay to reduce, let us say, the level of marijuana use or homosexual encounter.

If, in fact, we could get reasonably accurate measures of the social cost of crime, it would be an important step toward evaluating the optimal level of law enforcement. It would allow us to compare the marginal costs and benefits of programs of law enforcement and would pave the way to answering both the questions of whether the police are producing at minimum cost and how much and what kinds of police services are desired. For this reason, further analysis of social cost is important. Nevertheless, this approach to the measurement of police output does not provide a short-run solution to the need for measuring police output.

\section{Cost-Effectiveness Analysis}

The concept of cost-effectiveness is closely related to benefit-cost analysis; how-

\footnotetext{
${ }^{12}$ For example, Becker, in Crime and Punishment: An Economic Approach, supra note 6, indicates that the "social value of the gain to offenders" from committing a crime should be included in any calculation of benefits, while Stigler, in The Optimum Enforcement of Laws, supro note 6, argues against its inclusion.
} 
ever, output is not measured in dollars. It is equally useful in answering the question of whether a given level of output is being produced at minimum cost, but it is less useful in determining the optimal level of production. The great advantage of this technique is that it can be used with respect to most measures of output.

Suppose that we were considering a program to increase the effectiveness of the police response by making it faster. Our objective is to reduce crime by interrupting a larger number of crimes in progress. We might choose to measure the effectiveness of the program in terms of its effects on the incidence of crime as before. However, there are two problems with this approach: depending on the size of the program, this measure may or may not be sensitive to changes in response time, and it may be difficult to isolate the effects of a decrease in response time from other factors. Obviously, the faster the police arrive, the greater the probability of interrupting a crime in progress. This, in turn, can be assumed to reduce crime rates both because of the deterrent effect of increasing the probability of arrest and because by catching and incarcerating more criminals there will be fewer at large.

Using the cost-effectiveness approach, one would determine alternative ways of producing each level of effectiveness and the cost of each alternative. Proceeding in this way one would ascertain the minimum-cost alternative for each level of effectiveness. This is equivalent to determining the most efficient way of producing each fixed level of output. In order to decide the optimum level of output, however, the decision-maker must trade off increments in cost against measured increments in production. In this case, the decision-maker would also have to be able to relate increases in measured performance with changes in the ultimate objective. For example, in the case of police response time and its relation to the likelihood of interrupting a crime in progress, he should know that unless the response time is less than fifteen minutes, there is a low likelihood of interrupting a reported crime in progress. Suppose, for the purpose of discussion, that if the response time were ten minutes there would be a one-in-ten chance of interrupting a reported crime in progress, whereas there would be a nine-in-ten chan'ce if the response time were two minutes. In this case the critical range would be between ten minutes and two minutes. As long as this is known and accounted for in the analysis, it presents no special difficulties. The decision-maker would take into account that changes in measured performance are to be weighted differently at different points in the scale.

Significant problems arise when the cost-effectiveness framework is used to evaluate alternative programs to improve police response in different communities. Assume that you were given the responsibility of allocating a fixed budget to police departments for programs to improve their response capability and that your job was to allocate these funds so as to maximize the increase in police response capability. Suppose that you had before you two proposals from two police departments in cities of identical size, each of which would exhaust your entire budget. 
The proposal from city $A$ would result in a decrease in response time from one hour to thirty minutes, whereas the proposal from city B would reduce response time from ten minutes to seven minutes. Using the response time alone as a measure of effectiveness, the increase in the level of effectiveness of city $A$ is ten times as great as that for city B. Since the costs are the same in both, the costeffectiveness of city A's program would be ten times as great as the cost-effectiveness of city B's program. However, a reduction in response time from one hour to onehalf hour will have virtually no effect on the number of crimes interrupted, whereas a reduction from ten minutes to seven minutes will have a very significant effect. Therefore, if one were to choose response time as a measure of effectiveness and to allocate money to programs on the basis of this measure, the result would be a gross misallocation of resources. While a complete discussion of the mathematical properties of output measures is beyond the scope of this paper, the message is clear. Care must be taken in selecting the quantitative measures for given objectives in order to insure that these measures have the properties necessitated by the purposes for which the measure is to be used. In this case, differences at various levels of output at different locations must not be valued equally. Exactly the same point applies to finding the level of output at which per unit costs are minimized. Depending on the scale of measurement, the minimization of per unit cost will require totally different production decisions.

\section{III}

\section{Basic Approaches to Measurung Police Output}

There have been several attempts to define a procedure for measuring police output. A number of the more important of these are reviewed and analyzed in this section of the paper. Approaches to the measurement of police output fall into four general categories. One approach has been to measure the output of the police in terms of the cost of inputs, or the per capita expenditures on the police. A second approach has been to measure the output of the police in terms of the relationship of intermediate products-arrest rates, response times, and so forth-to overall law enforcement. A third approach has been to choose a measure of final output, such as the crime rate or the probability of an individual's becoming a victim of a crime, to evaluate the effectiveness of the police. Finally, some effort has been made to measure the output of the police in terms of the dollar value of benefits. These four approaches do not as yet provide a completely satisfactory basis for any of the uses of police output measures discussed in the previous section.

\section{A. Cost of Inputs}

In using the dollar value of inputs as a measure of police outputs, there is an implicit assumption that increased spending for police services will produce more of 
what is desired from that service. A further implicit assumption is that the additional funds will be used efficiently. A problem with the latter assumption is that the efficient use of funds cannot be determined independently from a measure of output. For purposes of social accounting, the outputs of public services have traditionally been valued as equal to the direct cost of providing them. By definition, an additional dollar input will produce an additional dollar of output; and if one spends more, one will get more. However, to measure output by automatically equating it with input is of little use if one wishes to use the output figure for the purpose of evaluating the allocation by the police of these resource inputs. Nor does output measured in terms of input provide a basis for comparing one police program to another, either in terms of their absolute level of effectiveness or in terms of their cost-effectiveness. Furthermore, expenditure data cannot by itself be used to estimate whether there are increasing returns to scale in the provision of police services. By definition, there are constant returns to scale when police output is measured in terms of dollar inputs. While input cost data is important in determining the appropriate level of expenditure on police services, it cannot simultaneously be used as an output measure against which to compare these costs. Therefore, aside from social accounts, the primary use of measuring outputs by inputs is contracting for police services.

One interesting study designed to assess whether there are economies of scale in the provision of police services was performed by Werner Hirsch as part of an attempt to determine the expenditure implications of metropolitan growth and consolidation. ${ }^{13}$ As is suggested in the foregoing comments, he could not use police expenditures alone as a measure of output in such a study. To get around this problem, he uses an index of the scope and quality of police services based on the independent ratings of five police experts. ${ }^{14}$ The index incorporates their judgement, as police experts, on the total strength and capability of the police force and the basic conditions bearing on the policing problem. Hirsch then uses multiple regression techniques to estimate per capita expenditure as a function of not only this index of quality but also of other variables such as population, miles of streets, and population density.

Hirsch concludes from his data that for the police and for all but a small group of municipal services no significant economies of scale exist. On this basis he dismisses arguments for metropolitan governmental consolidation which are based on alleged per capita cost savings. However, Hirsch's model involves methodological difficulties which, in fact, make it impossible to draw any conclusions regarding the existence or non-existence of scale economies from his results. The model, as specified, is not such that one can conclude that there are no economies

\footnotetext{
${ }^{13}$ Hirsch, Expenditure Implications of Metropolitan Growth and Consolidation, 4I REV. EcoN. \& STATISTTCS 232 (I959).

${ }^{16} 1 d$. at 237 .
} 
of scale from the fact that per capita expenditures do not increase with increases in the number of people served or with increases in the area served..$^{15}$

\section{B. Intermediate Products}

The second approach to measuring police output is to use some measure of the intermediate products of the police as an indicator by proxy of the final output. A minimum requirement for such a proxy is that there exist reasons for believing that variations in this proxy will show a high correlation with changes caused in the final output. For example, if there were evidence that the arrest rates were negatively correlated with crime rates, then this might provide a good proxy for police performance. In addition, the proxy should not be such that it can be varied by discretionary action of the police without any corresponding change in the final output. For example, arrest rates might be altered strictly by a police decision to reduce the evidence required for arrest while the number of crimes committed and the number of persons convicted might change little, if at all.

Another problem encountered is that the police do not produce a single product but instead, several products, some of which are not related to law enforcement. In fact, in terms of the time expended by police personnel a relatively small amount is directly related to crime control as compared with general social service functions. ${ }^{16}$ Even in the case of crime-related activity, there are a number of functions that are performed and each has a particular effect with respect to the reduction of different crimes. This creates two serious practical problems for the measurement of police output. First, different measures of intermediate products or functions may be proxies for different outputs which must be assigned weights before they can be compared. Second, if one is trying to measure the cost-effectiveness of lawenforcement programs, one must subtract police expenditures for social service functions in order to arrive at a figure reflecting the net cost with respect to crime. Unfortunately, there are virtually no data on police costs that are delineated as to program. This makes the task exceptionally difficult.

One attempt to measure police output in terms of the intermediate services performed was carried out by Schmandt and Stephens. ${ }^{17}$ They divide police services into sixty-five categories, each representing specific activities of the police. Examples of categories are motorcycle and foot patrol, criminal investigation, radio communication, and radar speed units. A service index for a police force is then derived by adding the number of functions performed. The weakness of such an index is apparent. It does not account for either the quantity or quality of each subfunction. Furthermore, since there is no weighting system, all subfunctions are

\footnotetext{
${ }^{15}$ See Tiebout, Economies of Scale and Metropolitan Governments, 42 Rev. EcoN. \& Statistics 442 (1960).

${ }^{10}$ See Misner, The Urban Police Mission, 3 Issues in Criminorogy 38 (Summer, I967) or Chicago Police Department Operations Research Task Force, Allocation of Resources in the Chicago Police Department, 1969 (Chicago) (Mimeographed).

${ }^{17}$ Schmandt \& Stephens, Measuring Municipal Output, 13 NAT'z TAx J. 369 (1960).
} 
regarded as of equal importance to the police mission. Schmandt and Stephens were aware of these weaknesses, but they believed the index to be still useful. Yet, such a functional index would be of limited value for the three central uses of output measures: evaluating operating units, program planning, and the contract pricing of police services. For example, Schmandt and Stephens conclude that their index indicates that police forces serving larger populations provide more services, and thus are better forces. Alternatively, this index may only indicate that larger police forces have more specialized units within their organization, not that they provide more services per capita than a smaller force.

\section{Statistical Representatives for Final Output}

Alternative proxies for the crime-related output of the police are number of arrests, ${ }^{18}$ the clearance rate, ${ }^{19}$ and police response time. ${ }^{20}$ Arrest rates and clearance rates suffer from the defect that they are subject to discretionary change by the police without yielding corresponding changes in the final output and that changes in these rates may occur as a result of changes in factors totally unrelated to police performance. For example, increased reporting could result in more arrests but a lower clearance rate without a change in police activity. Using the first measure, output would go up; using the second, it would go down. Police response time, on the other hand, has a number of desirable properties; however, a detailed discussion of response as a proxy for police output will be deferred until the final section. of this paper.

Two measures representing the level of final output of the criminal justice system that must be considered are the actual rates of crime and the probability of an individual being victimized. ${ }^{21}$ Both have the obvious drawback that they do not differentiate among crimes and that it is difficult to isolate variations in these measures resulting from police activities from changes resulting from other factors. Nevertheless, they are desirable in that they relate closely to what people ultimately want from law enforcement. They would be very useful if we could include in our consideration control factors for socio-economic differences in the underlying population. Research dealing with the socio-economic factors of crime has, for the most part, been carried out by criminologists and sociologists and has not been brought to bear systematically on problems of evaluating police production and resource allocation. An important next step for criminal justice research is to coalesce these two bodies of literature.

It is of interest to note the different implications for the police that are implicit

\footnotetext{
${ }^{18}$ See Shoup \& Mehay, Program Budgeting for Urban Police Services, Institute of Government and Public Affairs, 197I (University of California-Los Angeles, Los Angeles) (Mimeographed).

${ }^{10}$ See Votey \& Phillips, The Law Enforcement Production Function, I969 (University of CaliforniaSanta Barbara, Santa Barbara) (Mimeographed).

${ }^{20}$ For discussion of the use of police response time, see Larson, On Quantitative Approaches to Urban Police Patrol Problems, 7 J. Resenrch in Crime and Delinguency 157 (1970).

${ }^{21}$ See President's Commission on Law Enforcendent and the Administration of Justice, Crime AND ITs IMPACT-AN Assessment Ch. 5 ( 1967$)$ for preliminary examples of victimization studies.
} 
in choosing the probability of being victimized, as opposed to the crime rate, as the measure of output. If we choose the former, then "crimes without victims" have no effect on the level of justice; they are given zero weight in computing the crime rate. If what we really are after is increasing our security in the sense of avoiding victimization, the implication is that we should not be enforcing laws against crimes of mutual consent. The purpose of this paper is not to judge the desirability of existing laws; it is to point out that the output measure which is chosen will have important implications for law enforcement decisions. If certain crimes are given zero weight, then an optimally run system will not commit resources to reduce their number. To avoid unintended, incentive effects, the decision-maker must be aware of the consequences which may be produced by the adoption of a given performance measure.

\section{The Dollar Value of Benefits}

An example of the fourth type of measure, the use of cost-benefit analysis in law enforcement, is given in research conducted by Thurow and Rappaport. ${ }^{22}$ They investigate the derivation of an optimal strategy for the enforcement of the minimum wage, overtime pay, and equal pay provisions of the Fair Labor Standards Act. In this specific case, both the benefits and costs are well defined, narrow in scope, and easily quantified in monetary units. The benefits resulting from enforcement are merely the illegally lost wages restored to workers through enforcement, and the costs are the operating costs of the organization that conducts investigations specifically into these violations. Since sufficient data exists, Thurow and Rappaport can draw detailed conclusions and are able to avoid the major methodological difficulties inherent in a more general application of cost-benefit analysis.

\section{A Functional Approach to Police Output}

While police output should ideally be measured in terms of its contribution to the final output of the criminal justice system as evidenced by the reduction in the social cost of crime, a weighted crime rate, the probability of being victimized, or some other gauge, it does not seem likely that such indicators will totally meet measurement needs in the near future. The two critical problems are isolating changes in these measures resulting from police activity and defining generally accepted operational rules for computing the measuring index.

One way to circumvent these two problems is to find an intermediate output or function of the police that is positively related to the desired final output. The disadvantage with this approach is that one needs additional information to determine whether the police are being effective in terms of the performance of the

\footnotetext{
${ }^{22}$ Thurow \& Rappaport, Law Enforcęment and Cost-Benefit Analysis, 24 Pub. Finance 48 (1969).
} 
system as a whole. Consider, for example, police response time. Most variations in police response time will be related to police capability, and the average response time can easily be computed. The difficult, unanswered question is how a given change in response time will affect the number of crimes.

The approach adopted here is to analyze the basic variables through which police activity contributes to the reduction of crime and then to look for measures of performance that relate to these variables. Given the basic laws and the penalties they provide for various crimes, the police can contribute to the reduction of crime through two mechanisms. Their activity deters crime by changing the probability of arrest and by altering the rewards of criminal activity. For example, quick police response or good detective work will increase the probability that the criminal in a given crime will be apprehended and convicted. On the other hand, efforts to improve security-such as locking doors and other measures designed to make crime more difficult-and efforts by the police to interrupt the distribution of stolen goods will have a deterrent effect because they reduce the expected gain from crime. ${ }^{23}$ The apprehension and conviction of each criminal has the additional effect of removing a criminal from society or at least placing him under effective control which prevents him from committing further crimes.

Shoup and Mehay also point out a third approach to crime control, the alleviation of conditions that lead to crime. ${ }^{24}$ While this is indeed an important strategy for reducing crime, the underlying conditions which produce crime are largely beyond the control of the police. Few police programs are directed to removing the basic social conditions that produce criminal activity. There are exceptions, of course, such as police-community relations programs that may reduce crime producing tensions. By and large, however, such efforts are minimal.

The critical factors underlying apprehension and conviction are ( $\mathrm{I}$ ) information or intelligence, (2) police response, and (3) police investigation. If we were to measure police performance with regard to the probability of apprehending and convicting the criminal for a given crime, then we might want to use a weighted index of police capability in these three areas. If, however, one capability dominates the other three in importance, then a measure of that capability would be a good proxy for police performance related to apprehension and conviction. Suppose that the information coming to the police from the public at large is exogenously determined, that is, police activity itself has little effect on the public's willingness to provide information to them. In that case, the effectiveness of police activity related to apprehension and conviction will depend on response time and detective capability alone. It is, however, the feeling of many policemen of all ranks that for most crimes the probability of an arrest is virtually zero unless the criminal is caught in the act or there is an eyewitness identification. The latter is largely

\footnotetext{
${ }^{23}$ An examination of the nature of deterrence can be found in Lind \& Block, A Choice Theoretic Model of Criminal Deterrents, r972 (Stanford) (Mimeographed).

${ }^{24}$ Shoup \& Mehay, supra note I8, at A-2.
} 
beyond the control of the police. It appears that for many crimes, investigation is not effective. This position is to some extent supported by existing data, although not conclusively documented. ${ }^{25}$

As was discussed previously, a decrease in police response time does not have the same effect on the probability of interrupting a crime at all ranges of the scale. A better measure of police response capability would be the probability of interrupting a crime in progress as a function of the average response time. One could then evaluate the importance of a quick response for various types of crimes. If the seriousness of various types of crimes are weighted, then this scale can be used as a basis of a priority system for police dispatching. This response time function would take into account both the seriousness of the crime and the relative speed of response required. In any case, more rapid police responses will lead to a higher probability of interrupting crimes of all types. Therefore, the average probability of interrupting a crime in progress, where the average is taken over the entire population of serious crimes, would provide a reasonably good measure of overall police capability.

This does not mean that detective capability should be ignored entirely. It is obviously important for the police to have investigatory capability; but if it is true that the major impact of the police with regard to apprehension and conviction comes from interrupting crimes in progress, then one should look very closely at the cost-effectiveness of response capability as opposed to detective capability. One difficulty with this measure of performance is that it neglects the police role in obtaining information that may contribute to arrest and apprehension. In other words, it does not take into account the possibility of the police improving their performance through their own intelligence system or through increased cooperation with the public.

A measure of police performance which would reflect all three capabilities is the rate of conviction resulting from arrests. If the performance of the prosecutor and the courts is taken as given, then the performance of the police with regard to apprehension and conviction can be measured by the ratio of persons convicted to the total number of criminal acts committed. It is important here to use the total number of crimes as the numeraire and not the number of reported crimes in order to avoid crediting the police with a high measure of performance merely because many crimes never were reported to them. A problem with this measure is that the number of convictions not only depends on the arrest rate but also on court loads and the decisions by the prosecutor with regard to prosecution. If the ratio of arrests to convictions remained constant, then the ratio of arrests to crimes committed could be substituted for the conviction rate as a measure of police performance. It is, however, desirable to measure both rates and to analyze the ratio of arrests to convictions. If this ratio goes up, it indicates that either there are problems relating

\footnotetext{
${ }^{25}$ See President's Commission on Law Enforcement and the Administration or Justice, Science and Technology 93 (1967).
} 
to prosecution and the courts or that the police are making arrests on less evidence.

It should be noted that throughout this paper the actual crime rate has been used in various measures of police output. At the present time, there are few statistics on actual rates of crime. Such statistics can be obtained by sample survey techniques. It is of extreme importance that in the future this data be collected on a more systematic basis. In the short run what is required for the evaluation of police performance is the development of special surveys to get necessary information for particular studies.

Reduction of the financial reward of specific crimes and the resulting decrease in the incentive for committing these crimes is an important deterrent effect of police activity. In order to evaluate police performance in this area it is critical that we do further studies of the actual payoffs of various types of crime so that we can determine the rates of return to individuals engaging in such crime. Also, one must compare this information with data on alternative sources of income for these individuals. In many cases, crime is a direct substitute for legal employment or for investment. ${ }^{26}$

Almost no empirical work has been done relating the gain from crime to alternative sources of income for the criminal and relating both to the decision to engage in crime. Furthermore, very little empirical work has been done relating the rewards from various types of crime to the several activities of the police. This is an extremely promising area for study. It would help answer such questions of police strategy as whether it is more effective to prevent burglary by apprehending and convicting burglars or by impeding the distribution system for stolen goods. The studies would explore such issues as how much the price paid for stolen goods would have to be reduced to make theft unprofitable.

\section{ConcLusion}

The pursuit of justice requires the use of scarce resources and, thus, competes with the pursuit of other desirable ends. Therefore, justice, like these other ends, is not a matter of all or none, but a matter of more or less. How much justice is produced is an important choice and this choice is part of overall resource allocation. To rationally decide the question of how much to spend on justice one must weigh the alternatives; that is, a rational allocation of resources to the functions of the criminal justice system requires a comparison of the costs and benefits where the costs represent the cost of foregone alternatives.

A conceptual framework for making these tradeoffs is developed when one considers that crime imposes a cost and that the function of the criminal justice system is to reduce these costs through the control of crime. Within this framework, one can compare the gains from crime reduction with the costs of law enforcement including both the resource costs and other uncompensated costs that may result

\footnotetext{
${ }^{20}$ Lind \& Block, supra note 23.
} 
from law enforcement. An optimal system would be one which minimized the combined costs of crime and law enforcement.

The police are a critical part of the criminal justice system, and ideally one would measure their performance in terms of their contribution to the output of the total system. However, because there are conceptual difficulties inherent in the measurement of the cost of crime and because the police are only one part of the criminal justice system, other measures of police performance must be developed to serve the practical needs of planning and evaluation, management control, and contracting. To be of practical value, as well as conceptually consistent with higher level objectives, these output measures must be tailored to their intended uses.

To evaluate overall police performance, it is important to note that the two primary ways that the police can reduce crime is to increase the probability of arrest and conviction and to reduce the payoff from crime, either by making crime more difficult and therefore more costly, or by reducing the actual financial gain to the criminal. The success of the police in doing the former can be measured by the ratio of arrests leading to conviction to actual crimes committed. Their success in reducing the payoff from crime can be measured by computing the actual payoffs and costs of various types of crime. The data requirements in both cases are a problem. The first requires a measure of actual rather than reported crime, as well as data on convictions relating to crime committed in particular police jurisdictions. The second requires data on property losses from crimes, as well as a measure of the cost of committing crime.

While conceptual difficulties and data problems do exist, it is possible to develop and use performance measures for police programs. This is imperative because the effective planning, evaluation, and implementation of police programs requires the definition and measurement of police output. No one measure will satisfy all needs. One must carefully analyze alternative measures of performance to determine if they satisfy the criteria for particular uses. Only when we have developed satisfactory measures of performance can we know what the police are producing, if they are producing at minimum cost, and whether we are buying too much or too little police service. 